\title{
Epigenética en cáncer
}

[Epigenetics in cancer]

\author{
Marta Elena Hernández-Caballero ${ }^{1}$
}

${ }^{1}$ Facultad de Medicina, Benemérita Universidad Autónoma de Puebla (BUAP)
ehdezc@yahoo.com

\section{Resumen}

Las células contienen información determinada por el genoma propio del organismo al que pertenecen, lo cual le permite el desarrollo y diferenciación propios de su especie, en este sentido la información epigenética constituye una capa adicional de información reguladora que vuelve más complejos los procesos celulares. La metilación del DNA es la marca epigenética de inactivación más conocida y como el proceso reversible que es, consiste en un fenómeno dinámico que cambia durante la vida de la célula. Los cambios epigenéticos inciden directamente en la conformación que adquiere la cromatina, con lo que se regula el cómo se expresen los genes y su actividad, a su vez, depende de modificaciones postraduccionales en las proteínas histonas. Las histonas al igual que el DNA también pueden presentar modificaciones epigenéticas.

El cáncer es una patología heterogénea que durante mucho tiempo se creyó era el resultado únicamente de la adquisición de mutaciones genéticas o rearreglos cromosómicos, que desembocaban en la pérdida del funcionamiento de genes encargados de evitar el crecimiento celular descontrolado y de la desregulación de la actividad de genes encargados de promover la proliferación. No obstante, la expresión adecuada de los genes es fundamental para mantener el fenotipo celular normal, y el control de dicha expresión va más allá de la sola presencia de una secuencia genética sin cambio. Sin embargo, las alteraciones epigenéticas que 
preceden y contribuyen al inicio del desarrollo de un cáncer aún no se conocen de forma precisa.

Actualmente la metilación de DNA es la principal marca epigenética más ampliamente estudiada. La diversidad en el uso de técnicas para realizar este cometido va desde métodos sencillos como el uso de enzimas de restricción sensibles a la metilación, para digerir DNA genómico y analizar pequeñas regiones de DNA, pasando por el uso de bisulfito de sodio para analizar el estado de metilación en las citosinas hasta los métodos actuales de secuenciación a gran escala que permiten el análisis simultaneo de gran cantidad de muestras y de amplias regiones del genoma completo, llegando a analizar hasta 3 millones de variantes genéticas en un individuo. A la par, se ha desarrollado software especializado en epigenética, permitiendo conocer la ubicación de sitios de metilación para luego hacer su búsqueda en muestras biológicas y se han desarrollado programas complejos para el análisis de datos masivos obtenidos a través del uso de plataformas basadas en hibridación (microarreglos) y la secuenciación masiva con diversas afinidades (DNA-seq, RNA-seq, ChIP-seq, FAIRE-seq, ATAC-seq, MeDIP-seq, MBD-seq) y WGBS. Los cambios epigenéticos aberrantes en el cáncer pueden ser evidentes desde etapas tempranas, lo que ha llevado a pensar que, esta desregulación precede de hecho a los eventos tumorales transformadores preliminares clásicos (mutaciones de supresores y/o protooncogenes e inestabilidad genómica). Entre las alteraciones epigenéticas más reconocidas en los tumores está el silenciamiento asociado a hipermetilación de islas $\mathrm{CpG}$ en los promotores de los genes supresores como CDKN2A y RASSF1.Aunado a esto, los miRNAs también pueden actuar como supresores $u$ oncogenes en diferentes tipos de cáncer. Es por esto que, las modificaciones epigenéticas son un componente importante en la etiología del cáncer y debido a su reversibilidad constituyen blancos terapéuticos prometedores para diagnostico 0 tratamiento y potencial como posibles biomarcadores.

Palabras clave: Alteración del patrón de metilación, Cáncer, Epigenoma, Fármacos epigenéticos 
En este capítulo se detallarán los fenómenos epigenéticos que subyacen al control aberrante del proceso de metilación y como contribuyen al desarrollo del cáncer. Las células tienen información determinada por el genoma propio de cada organismo y de su especie, para el desarrollo y diferenciación de sus células, la información epigenética en este sentido constituye una capa adicional de información reguladora que vuelve más complejos los procesos celulares. Este fenómeno se puede comprender mejor si se piensa que todas las células de un organismo a pesar de compartir la misma información genética, tienen la capacidad de diferenciarse en células tan diferentes como, eritrocitos que producen hemoglobina, condrocitos que producen la matriz cartilaginosa o células de musculo especializadas en la contracción. Entonces ¿Cómo pueden las células expresar solo un grupo de genes y silenciar o apagar otros? La respuesta es, a través de la actividad de factores de transcripción específicos para cada linaje celular y mediante marcas epigenéticas en el genoma. Las marcas epigenéticas le dan la estructura al cromosoma demarcando los extremos y el centro del mismo, señalan el principio y el fin de un gen y especialmente, pueden alterar la forma en que se lee un gen, provocando su inactivación o activación transcripcional aberrante. En resumen, los mecanismos epigenéticos permiten un uso selectivo del genoma, uso que puede desregularse en patologías como el cáncer.

\section{Introducción}

Los mecanismos epigenéticos incluyen la metilación del DNA, modificaciones de las histonas asociadas al DNA y modificaciones en los RNAs no codificantes, además del propio posicionamiento de los nucleosomas y su composición, y todos ellos trabajan de manera cooperativa para controlar la expresión de los genes.

Básicamente la metilación del DNA es una marca epigenética de inactivación y dado que este es un proceso que puede ser revertido, es un fenómeno dinámico que cambia durante la vida de una célula. 
La metilación diferencial del DNA se puede observar cuando se comparan tejido sano con tejido enfermo de diversas patologías, desde la esquizofrenia, epilepsia, obesidad o artritis reumatoide hasta el cáncer. El DNA puede encontrarse en dos estados alterados, hípermetilado si el nivel de modificaciones genómicas aumenta e hipometilado, si disminuye. Las modificaciones que dan lugar a esos patrones de metilación anormal representan un punto importante para comprender la susceptibilidad a las enfermedades.

\section{Mutaciones que alteran los patrones de metilación}

El cáncer es una patología heterogénea que durante mucho tiempo se creyó era el resultado únicamente de la adquisición de mutaciones genéticas o rearreglos cromosómicos, que desembocaban en la pérdida del funcionamiento de genes encargados de evitar el crecimiento celular descontrolado y de la desregulación de la actividad de genes encargados de promover la proliferación. Sin embargo, el creciente interés de diversos estudios en la década del 2000 permitió comprender que la expresión adecuada de los genes es fundamental para mantener el fenotipo celular normal, y que el control de dicha expresión va más allá de la sola presencia de una secuencia genética sin cambio. Extrapolaciones a partir de estudios de secuenciación del cinoma (conjunto de proteínas cinasas expresadas en el genoma de un organismo) y el exoma (la parte del genoma conformada por los exones), han sugerido que las células cancerosas en algunos tipos tumorales pueden llevar más de un millón de mutaciones por sustitución de bases en su genoma. Por lo tanto, las células tienen suficientes aberraciones genéticas para la carcinogénesis y progresión tumoral, pero evitan la acumulación de demasiadas alteraciones perjudiciales (lo que se conoce como el concepto "just right" para la inestabilidad genética).

Debido al amplio estudio de la metilación en diversos tumores se ha descubierto que algunos genes se encuentran alterados de manera frecuente sin importar el tipo de tumor analizado. Entre las mutaciones más frecuentes en el cáncer humano descubiertas gracias al uso de la secuenciación masiva, están las mutaciones en 
los genes que codifican las subunidades del complejo SWI/SNF o del complejo BAF (Brg/Brahma-associated factors). Se estima que alrededor del $20 \%$ de todos los canceres tienen mutaciones en los genes que codifican las subunidades de los complejos de remodelación de cromatina dependientes de ATP, SWI/SNF.

Por lo tanto, el inicio y progresión del cáncer también puede ser el resultado de cambios en las modificaciones tanto de DNA como de histonas, es decir, puede ser el resultado de cambios en el epigenoma. Hay que recordar que al hablar de modificaciones se están considerando también la metilación del DNA y modificación covalente de las histonas o RNAs no codificantes.

Sin embargo, las alteraciones epigenéticas que preceden y contribuyen al inicio del desarrollo de un cáncer aún no se conocen de forma precisa. Esto se debe a que la mayoría de los estudios realizados comparan células con un proceso tumoral ya expresado contra su contraparte normal, haciendo difícil dilucidar que alteración epigenética es la que inicia la enfermedad.

Es importante señalar que también se han encontrado mutaciones aún en las propias enzimas que median las modificaciones epigenéticas, como las que afectan a DNMT3a, que están presentes en $22 \%$ de los casos de leucemia mieloide aguda y se asocian con un mal pronóstico. La mutación de la dioxigenasa de metilcitosina TET2 afecta a casi el $15 \%$ de los canceres mieloides y parece tener un papel en la función de las células trocales mieloides ya que ratones mutantes con deficiencia de Tet-2 desarrollan mieloproliferación.

\section{Tecnologías aplicadas al estudio de la epigenómica}

El término epigenoma surgió para describir todas las modificaciones epigenéticas en el genoma, de manera que el epigenoma controla el genoma tanto de procesos celulares normales como de procesos anormales. El conocer los cambios en el estado de la metilación es útil, ya que puede servir como un marcador de diagnóstico o pronóstico en un cáncer. Esto es especialmente importante si se trata de marcadores tempranos presentes en células a las que se tenga fácil acceso que 
no sean necesariamente las del tumor, como sería el caso de células presentes en la orina de un paciente afectado por cáncer de próstata o una muestra de sangre para analizar tumores como el de colón o mama.

Básicamente, gracias al análisis de miles de muestras de tejidos tumorales y de tejidos sanos, es que se han podido identificar alteraciones epigenéticas. Actualmente la metilación del DNA es la principal marca epigenética más ampliamente estudiada. La diversidad en el uso de técnicas para realizar este cometido evolucionó desde métodos sencillos, como el uso de enzimas de restricción sensibles a la metilación, para digerir DNA genómico y analizar pequeñas regiones de DNA, pasando por el uso de bisulfito de sodio para analizar el estado de metilación en las citosinas hasta los métodos actuales de secuenciación a gran escala, que permiten el análisis simultaneo de gran cantidad de muestras y de amplias regiones del genoma completo, llegando a analizar hasta 3 millones de variantes genéticas en un individuo.

Una herramienta muy útil ha sido la evaluación de la metilación del DNA a través de la conversión de citosinas no metiladas a uracilos mediante el tratamiento con bisulfito de sodio, básicamente ésta técnica se fundamenta en la conversión de $\mathrm{C}$ en $U$ siempre y cuando la $C$ se encuentre desmetilada, mientras que si ésta se encuentra metilada permanecerá como $\mathrm{C}$ no convertida. Posteriormente mediante amplificación por PCR las Cs convertidas serán reemplazadas por Ts, luego, comparando la secuencia convertida con la secuencia no convertida se puede conocer el estado de metilación de esa región. A finales de la primera década del año 2000 se acopló el tratamiento con bisulfito de sodio y la secuenciación de alto rendimiento permitiendo la obtención de perfiles de metilación del DNA en el genoma completo. Ya en el año 2011, se hizo posible el estudio de la metilación del DNA a través de todo el genoma usando el chip de Illumina Human methylation 450K (permitiendo el análisis de casi 500,000 sitios), abriendo así el camino para cientos de estudios de asociación de epigenoma completo (EWAS, por sus siglas en inglés). Los EWAS básicamente buscan asociaciones entre variaciones en la metilación del DNA y rasgos humanos complejos. 
Todas estas tecnologías son herramientas ampliamente usadas por diversos Consorcios como el proyecto ENCODE (Enciclopedia de elementos de DNA), el proyecto de epigenómica RoadMap del Instituto Nacional de Salud $(\mathrm{NIH})$ de Estados Unidos, el Atlas del genoma del cáncer (TCGA) o el Consorcio Internacional del genoma del cáncer, con la finalidad de crear bases de datos epigenómicos de acceso público a través de sus sitios web, para los investigadores que realizan trabajo de biología básica u orientado a enfermedades, donde pueden obtener genomas de referencia para comparar con sus resultados. El Consorcio Internacional del Epigenoma Human (IHEC) del cual forman parte los Consorcios antes mencionados, se ha propuesto analizar más de 1000 epigenomas de referencia, esto debido a que la información epigenética varía entre individuos, tipos celulares y estados celulares funcionales, además de que para hacer una detección exacta de cambios epigenéticos en pacientes, se requiere de la generación de un gran número de epigenomas de referencia.

Por otro lado, también muy de la mano ha ido el desarrollo de software especializado en epigenética, que cada vez es mayor. El software para análisis epigenéticos va desde aquellos programas que ayudan en la ubicación de sitios de metilación para luego hacer su búsqueda en muestras biológicas hasta programas complejos para el análisis de datos masivos obtenidos a través del uso de tecnologías actuales, como el uso de plataformas basadas en hibridación (microarreglos) y la secuenciación masiva utilizando plataformas basadas en diversas afinidades (DNAseq, RNA-seq, ChIP-seq, FAIRE-seq, ATAC-seq, MeDIP-seq, MBD-seq) y WGBS. En la siguiente tabla se enlistan solo algunas de las diversas herramientas informáticas implementadas para el análisis de cambios epigenéticos. 
Tabla 1. Programas utilizados para análisis de metilación

\begin{tabular}{|c|c|}
\hline Software & Función \\
\hline MethPrimer & $\begin{array}{l}\text { Diseño de iniciadores (primers) para PCR de metilación } \\
\text { basada en la conversión con bisulfito }\end{array}$ \\
\hline $\begin{array}{l}\text { Methyl Primer } \\
\text { Express }\end{array}$ & $\begin{array}{l}\text { Búsqueda de islas CpG y diseño de primers para } \\
\text { experimentos de metilación }\end{array}$ \\
\hline MethylPipe & Análisis de metilomas de DNA de alta o baja resolución \\
\hline compEpiTool & $\begin{array}{l}\text { En cooperación con MethylPipe hace un análisis integrando } \\
\text { otros datos epigenómicos, permitiendo la identificación de } \\
\text { enhancers, IncRNAs, estancamiento/dinámica de } \\
\text { elongación de RNA Pol II }\end{array}$ \\
\hline coMET & $\begin{array}{l}\text { Visualización de anotaciones genómicas a partir de EWAS } \\
\text { para analizar patrones de co-metilación }\end{array}$ \\
\hline MethGo & $\begin{array}{l}\text { Análisis de datos obtenidos de secuenciación de genoma } \\
\text { completo tratado con bisulfito (WGBS) }\end{array}$ \\
\hline meRanTK & $\begin{array}{l}\text { Análisis de alto rendimiento de datos de metilación de } \\
\text { citosinas en RNA }\end{array}$ \\
\hline Batman & $\begin{array}{l}\text { Análisis de perfiles de inmunoprecipitación de DNA (MeDIP) } \\
\text { generados usando arreglos de oligonucleótidos (MeDIP- } \\
\text { chip= o secuenciación de nueva generación (MeDIP-seq) }\end{array}$ \\
\hline
\end{tabular}

IncRNAs: RNAs largos no codificantes

\section{Modificaciones epigenéticas en cáncer}

La regulación epigenética en el cáncer es aberrante porque el epigenoma presenta cambios globales tanto en la metilación del DNA como en los patrones de modificación de las histonas. En tumores en etapas tempranas es común observar hipometilación global del DNA de las células tumorales (frecuentemente en regiones con baja densidad de CpG, en zonas de secuencias repetidas, DNA satélite y regiones asociadas con la lámina de la envoltura nuclear) e hipermetilación de 
promotores específicos en islas CpG y en las "costas" de las islas CpG con menor densidad de CpG (las costas son regiones a 2 kilobases de distancia a cada lado de la isla), lo que ha llevado a pensar que, ésta desregulación precede de hecho a los eventos tumorales transformadores preliminares clásicos (como lo son las mutaciones de supresores y/o protooncogenes y la inestabilidad genómica). La hipermetilación de islas $\mathrm{CpG}$ en un promotor conduce al silenciamiento del gen regulado por ese promotor, como ocurre con los genes supresores de tumores en las células cancerosas. La hipermetilación del DNA se usa para subdividir a los tipos tumorales malignos de los no malignos y del tejido no afectado. Los tumores con altos niveles de metilación del DNA se dice que tienen un fenotipo metilador de islas CpG (CIMP) y están asociados de forma predominante a un peor pronóstico en cáncer de vejiga, pulmón y próstata. En análisis de sobrevivencia en cáncer de mama, colorectal, leucemia y gliomas se han asociado con mejoría en la sobrevivencia y menor riesgo de metástasis. Sin embargo; a la fecha no se ha establecido un consenso en su asociación con la sobrevida.

Mientras que, la hipometilación de un promotor puede tener el efecto inverso en el gen regulado por ese promotor, provocando su activación aberrante, lo que tiende a ocurrir en los oncogenes y que se asocia con activación de genes requeridos para invasión y metástasis. Un efecto agregado a la hipometilación es que también puede causar pérdida de impronta. Comparando células normales con tejido tumoral se ha encontrado que los tumores presentan del $5-10 \%$ de menor metilación y se ha sugerido que los cambios en la metilación aparecen entre los estados de hiperplasia y neoplasia benigna, donde el DNA esta significativamente hipometilado en comparación con el tejido normal. La causa de la hipometilación global aún no está bien comprendida, pero puede haber desmetilación pasiva por la incapacidad de la metiltransferasa DNMT1 para completar el paso de metilación post replicación en el DNA hemimetilado o por oxidación de la $5 \mathrm{mC}$ por TET3.

La alteración epigenética más reconocida en los tumores es el silenciamiento asociado a hipermetilación de islas $\mathrm{CpG}$ en los promotores de los genes supresores: CDKN2A (codifica para p16), RASSF1, que es un gen supresor de tumor que 
controla el crecimiento tumoral por inhibición de la vía RAS y en la vida celular participa en la señalización apoptótica, estabilización de microtúbulos y progresión mitótica. Forma parte de las vías RAS/PI3K/AKT, RAS/RAF/MEK/ERK e Hippo, importantes en los tumores sólidos y es uno de los genes más frecuentemente metilados en diversos tipos tumorales que incluyen a los cánceres de hígado, próstata, vejiga, riñón, cerebro, pituitaria y gástrico.

La desregulación de las histonas metiltrasferasas y de las histonas desmetilasas en las histonas, también se ha asociado a una variedad de neoplasias incluyendo al cáncer de mama, próstata, pulmón y cerebro, siendo especialmente importante la regulación del estado de metilación de los residuos de lisina K4, K9, K27 y K36 en la histona $\mathrm{H} 3$.

Metiloma en cáncer de pulmón

El cáncer de pulmón es la causa líder de muertes relacionadas a cáncer en el mundo, se clasifica en dos subtipos principales: Cáncer pulmonar de células no pequeñas (NSLC), el cual representa $85 \%$ de los cánceres de pulmón y cáncer pulmonar de células pequeñas (SCLC) que se diagnostica en $15 \%$ de los casos. Fumar es un factor de riesgo para todos los subtipos, aunque se asocia particularmente al subtipo carcinoma de células escamosas, mientras que el adenocarcinoma es el subtipo predominante en los no fumadores. El descubrimiento de alteraciones genéticas tratables como las mutaciones en el receptor para el factor de crecimiento epidermal (EGFR) y la translocación AKLEML4 han favorecido la aparición de nuevas alternativas de tratamiento para los pacientes que desarrollan enfermedad metastásica. Se han encontrado alterados los niveles de metilación de diversos genes y los niveles de metilación varían de acuerdo a la histología del tejido pulmonar afectado y si este proviene de un fumador o de un no fumador.

EI NSLC tiene una alta tasa de recurrencia y se ha encontrado que la metilación de las regiones promotoras de los genes p16, cadherina 13 (CDH13), RASSF1A y APC 
está fuertemente asociada con recidiva precoz, debido a que la recurrencia después de la cirugía presenta una frecuencia más alta de metilación en CDKN2A y CDH13 que aquellos que no la desarrollan. De igual manera, el promotor de SOX17 está altamente metilado en tumores primarios y en muestras de plasma de tumores operables y de etapa avanzada, y se sugiere que influencia el tiempo de sobrevivencia del paciente. La hipermetilación del gen para la secretina (SCT) es útil para discriminar entre subtipos malignos y tumores malignos de bajo grado donde es menos frecuente.

Mediante un estudio de metilación de genoma completo se encontraron regiones diferencialmente metiladas en promotores de los genes CTNNAL1, CST1 NQO1, MELK1, DPT, HBEGF, DACH1, AGER, PTPRM y en regiones génicas de FOXM1, FERMT1, SLC7A5 y FAP.

En un estudio reciente se identificaron 4 genes hípermetilados en tumores primarios en etapas tempranas con una eficacia diagnóstica alta en fluidos bronquiales, al ser comparado con la citología convencional, la cual tiene la enorme desventaja de su baja sensibilidad y sin embargo, a pesar de ello, sigue siendo el método más utilizado para el diagnóstico. Los genes que se han encontrado asociados con el silenciamiento transcripcional son BCAT1, CDO1, TRM58 y ZNF177.

Metiloma en cáncer de colon

El cáncer colorectal representa la forma más común de cáncer gastrointestinal y ya en el 2012 de acuerdo a la Organización Mundial de la Salud ocupaba el tercer lugar como causa de muerte a nivel mundial, siendo más frecuente en países desarrollados. Se le clasifica de acuerdo a sus características clínicas, patológicas y genéticas, histológicamente se describe como la transformación maligna progresiva del epitelio normal del colon a un adenocarcinoma invasivo, lo cual es el resultado de la acumulación de aberraciones genéticas y epigenéticas adquiridas. Existen 3 mecanismos patogénicos propuestos para el desarrollo de este tipo de cáncer. La inestabilidad cromosómica (CIN) explica el $85 \%$ de los casos, la 
inestabilidad por microsatélites (MSI) y la presencia de un fenotipo metilador de islas CpG (CIMP). El subtipo CIN involucra la desregulación secuencial de genes supresores y oncogenes, incluyendo mutaciones en el gen APC (poliposis adenomatosa de colon), KRAS, C-MYC y entre las deleciones cromosómicas que presenta se incluye la pérdida del cromosoma 17p, que alberga al gen supresor TP53 (incluyendo al adenoma convencional). El subgrupo MSI está asociado con el síndrome de Lynch (Cáncer colorectal hereditario no asociado a poliposis), presenta hipermetilación y subsecuente subexpresión de genes de reparación de bases mal apareadas, (como MLH1, MSH2, MSH6, PMS2), este tipo de tumor tiene un buen pronóstico. Mientras que el subtipo CIMP es responsable de casi el $40 \%$ de los canceres colorectales, está caracterizado por la mutación de BRAF V600E y por hipermetilación del DNA en las islas CpG de los promotores de genes supresores.

La colonoscopia es el método de elección para detectar lesiones que con frecuencia dan lugar a tumores colorectales. Sin embargo, la invasividad del procedimiento y la falta de cooperación de los pacientes para mantener el seguimiento le restan eficacia al procedimiento como una forma de prevención. Por lo que muchos investigadores han apostado por la búsqueda de otros métodos tanto para el diagnóstico como para el seguimiento. Actualmente se han identificado genes con metilación alterada en los cromosomas 1, 5, 6, 8, 11, 13, 18, 19, 21 y 22, destacando la hipermetilación de los genes ZIC1 (factor de transcripción con dedos de zinc 1 del cerebelo) y KLOTHO (gen antisenescencia). En un análisis por microarreglos de biopsias de tejido tumoral, colitis ulcerosa y tejido sano, se observó la hipermetilación de SFRP1, SST, BNC1, MAL, SLIT2, SFRP2, SLIT3, ALDH1A3, TMEFF2, WIF1, permitiendo discernir entre lesiones precancerosas y cancerosas de tejido inflamado y de tejido saludable. Un buen ejemplo de la interacción entre genes para controlar el crecimiento celular tumoral está representado por la metilación de RASSF10, este gen frecuentemente se reporta metilado en canceres colorectales tempranos. Su expresión es crucial porque se encarga de activar a P53, quien tiene un papel fundamental en la regulación del ciclo celular y la apoptosis. 


\section{Metiloma en cáncer gástrico}

El cáncer gástrico es el cáncer de mayor prevalencia en Asia del Este, por lo que, en países como Corea o Japón se hacen de forma rutinaria tamizajes después de los 40 años debido a la disminución en la edad de muerte por este tipo de cáncer, en un esfuerzo por detectarlo a tiempo. Considerando también que la tasa de sobrevivencia es menor al 30\%, lo que lo hace un cáncer de alta morbilidad y mortalidad. Tradicionalmente el cáncer gástrico se divide en dos subtipos histológicos: intestinal y difuso. El subtipo intestinal se deriva de las células de la mucosa gástrica, caracterizado por estructuras glandulares bien diferenciadas, presentando etapas patológicas secuenciales como la gastritis crónica, atrofia, metaplasia intestinal y displasia. Mientras que el subtipo difuso se caracteriza por un crecimiento infiltrativo pobremente diferenciado sin etapas premalignas definidas y está asociado con una conducta agresiva y mal pronóstico. Sin embargo, en 2014 la Red del TCGA clasificó al cáncer gástrico en 4 subtipos: positivo al virus de Epstein-Barr (EBV), con inestabilidad en microsatélites (MSI), genómicamente estable y el subtipo con inestabilidad cromosómica.

El subtipo EBV al igual que muchos otros tipos tumorales presenta hipermetilación de los promotores de CDKN2A y RASSF1, además de hipermetilación en p14ARF, p15, p16INK4A, p73, TIMP3, E-cadherina, DAPK y GSTP1. Los cánceres gástricos del tipo MSI se caracteriza por una extensa hipermetilación, el tipo MSI se asocia con la ausencia de actividad en la reparación de apareamientos erróneos de bases del DNA. Debido al silenciamiento por hipermetilación, la característica más común de este subtipo es la hipermetilación del promotor de MLH1 (gen de reparación de apareamientos erróneos homólogo de mutL1), además de gran número de genes supresores de tumor como GATA5, OSR1, HHIP, PAX6 y POPDC3.

La carcinogénesis gástrica es un proceso multifactorial donde no solo la infección por Helicobacter pylori, el consumo de sal, tabaco, alcohol, historia familiar, gastritis atrófica 0 metaplasia intestinal son factores de riesgo. Esta patología frecuentemente es asintomática o causa síntomas no específicos en sus etapas iniciales, por lo que, para cuando los síntomas se manifiestan el cáncer ya ha alcanzado un estado avanzado. La infección por $H$. pylori es particularmente un 
factor carcinógeno determinante, ya que causa cambios en la metilación del DNA que se acumulan en la mucosa gástrica antes que las células cancerosas sean detectadas y la presencia de la bacteria es más alta en etapas tempranas y luego desaparece.

Diversos estudios han demostrado que la hipermetilación de los genes supresores CDH1, CDKN2A, MLH1 y RUNX3 se asocian con cáncer gástrico en etapa temprana.

\section{Metiloma en cáncer de mama}

En las mujeres el cáncer de mama es el tumor más frecuente y es la principal causa de muerte por cáncer en mujeres tanto de países desarrollados con de aquellos en desarrollo. La incidencia ha aumentado debido a la mayor expectativa de vida, la urbanización y el estilo de vida. Esta patología se divide en dos grandes tipos: el cáncer de tipo esporádico, cuando los cambios genéticos aparece en las células somáticas a través del tiempo (comprende alrededor del $90 \%$ de los tumores diagnosticados) y el de tipo hereditario, cuando el tumor se origina por mutaciones en la línea germinal principalmente en los genes BRCA1 y BRCA2, este último tipo solo da lugar al $5-10 \%$ de todos los tumores de mama.

De forma más específica, el cáncer de mama se clasifica en diversos subtipos moleculares con base a los genes que se expresan (sin embargo, en muchos países se usa aun de manera rutinaria la clasificación mediante inmunohistopatología). Se han definido 5 subtipos: Luminal-A, luminal-B, HER-2, normal-like y basal-like. Como en muchas patologías, la detección a tiempo es crucial ya que la sobrevivencia cae del $98 \%$ al $20 \%$ cuando el tumor se ha dispersado. Utilizando el Infinium Human Methylation27K Beadchip se ha encontrado hipermetilación de AKR2B2, COL6A2, GPX7, HIST1H3C, HOXB4, RASGRF2, TM6SF1, HIDR1H3C y AKR1B1, además de los previamente conocidos ARHGEF7, TMEFF2 y RASSF1A. RASSSF1 es un gen supresor de tumor que regula apoptosis y puntos de revisión del ciclo celular, se ha encontrado hípermetilado en el carcinoma in situ y en el cáncer invasivo, este cambio se ha correlacionado de manera inversa con la 
supervivencia global. De igual forma cuando RASSF1A y APC metilados son encontrados en suero, se les asocia con un mal pronóstico. Mientras que la sobre expresión de las proteínas HER-2 y EGFR está relacionada con la resistencia a múltiples fármacos y la disminución en la supervivencia de las pacientes. La hipometilación de TFF1 un gen que codifica para un pequeño péptido implicado en preservar la mucosa en el tracto intestinal, puede ser favorable, ya que se considera es un buen pronóstico en pacientes cáncer de mama con receptores a estrógenos y progesterona positivos.

Los tumores de mama triple negativos comprenden un grupo heterogéneo, de pronóstico variable y, representan un enorme reto para un manejo clínico efectivo. Se definen clínicamente por la ausencia en la expresión del receptor de estrógenos $(E R)$, receptor de progesterona (PR) y falta de amplificación y sobreexpresión de HER2 (receptor 2 para el factor de crecimiento epidermal), representan aproximadamente del 15 al 20\% de los cánceres diagnosticados y están asociados con alto riesgo de recurrencia y una sobrevivencia corta. En este tipo tumoral la sobreexpresión del gen WT1 está asociada a un mal pronóstico, WT1 es un factor de trascripción esencial para el desarrollo del sistema urogenital que al parecer también está implicado en este tipo de tumor.

BRCA1 es un gen cuya proteína juega un papel importante en la reparación de rupturas de la cadena doble del DNA, participa en regulación transcripcional y ubiquitinación entre otras funciones. La hipermetilación de su promotor es un mecanismo que conduce a la inactivación de BRCA1, su falta o baja expresión a causa de este fenómeno, se ve reflejada en la inadecuada reparación del daño al DNA y la consecuente acumulación de mutaciones en la célula. La metilación del promotor de BRCA1 se correlaciona con un peor pronóstico y con negatividad en el ER, PR y HER2 y no es un proceso epigenético exclusivo de los tumores de tipo hereditario.

Por otro lado, actualmente se sabe que los RNas también pueden tener una participación epigenética importante en el desarrollo de los tumores, por ejemplo, el RNA intergénico antisentido del transcrito HOX (HOTAIR) se ha encontrado 
reprimido y ha sido asociado con metástasis en cáncer de mama. De manera interesante, este RNA participa en la reprogramación del estado de la cromatina a través de su interacción con la histona metiltransferasa PRC2 y con LSD1, quien participa en la desmetilación de la histona H3K4. PRC2 se une al dominio 5' y LSD1 al dominio 3' de HOTAIR, de esta manera es capaz de regular modificaciones en la cromatina.

\section{Metiloma en cáncer de próstata}

El cáncer de próstata es la segunda causa de muerte más común en los hombres a nivel mundial, en Estados Unidos se reportan 220,800 casos nuevos y se estimaron 27,540 para el año 2015 , la mortalidad y morbilidad se deben principalmente a la invasión y metástasis. Los afroamericanos en particular experimentan una incidencia significativamente más alta de desarrollar cáncer de próstata, además de tener una presentación más agresiva, lo que se traduce en mayor probabilidad de morir a causa de la enfermedad, también tienen mayor incidencia de cáncer después de biopsias negativas con respecto a los caucásicos.

Este tipo de cáncer es una enfermedad multifactorial compleja en la cual, el principal reto es distinguir entre la enfermedad agresiva (de alto grado) y la indolente (de bajo grado), la precisión en ésta diferenciación es de suma importancia para reducir el tratamiento excesivo. La hiperactivación de la vía del receptor de andrógenos juega un papel central en el desarrollo del tumor. Inicialmente muchos tumores malignos dependen de andrógenos exógenos provenientes del flujo sanguíneo y la eliminación de la fuente es efectiva para la supresión del crecimiento del tumor en esta etapa. Sin embargo, mutaciones en el receptor para andrógenos, la síntesis de andrógenos endógenos y otras alteraciones vuelven al tumor independiente de la presencia de andrógenos externos y conducen a I fracaso del tratamiento. La metilación de varios genes se ha encontrado correlacionada con la recurrencia de la enfermedad. Entre ellos el supresor de tumor RASSF1, la glucoproteína de superficie CD44, APC, la ciclooxigenasa PTGS2, el gen de la ciclina D2, CCND2 y RARB (gen del receptor beta del ácido retinoico) se encuentran hípermetilados. La 
metilación del promotor de RARB observada en biopsias de tejido histopatológicamente negativo sirve para predecir cáncer en biopsias de seguimiento hechas dentro de un periodo de 24 meses con una sensibilidad del $84 \%$.

Aunado a lo anterior, la proteína del grupo Polycomb EZH2, que es una metiltrasferasa de histona H3 lisina 27 (H3K27) se ha encontrado sobreexpresada en cáncer de próstata metastásico.

\section{Metiloma en leucemia}

La leucemia mieloide aguda ( $A M L)$ es un grupo heterogéneo de enfermedades que tienen la característica común de proliferación de células mieloides inmaduras en la médula ósea y/o sangre. Históricamente eran clasificadas por la morfología y fenotipo citoquímico de las células tumorales bajo el Sistema de Clasificación Franco-americano-británico. Actualmente se clasifican como AML con anormalidades genéticas recurrentes, $A M L$ con cambios relacionados a mielodisplasia, neoplasias mieloides relacionadas a terapia y AML no especifica.

La AML es la leucemia aguda más común en los adultos y está entre las más letales, en Estado Unidos la incidencia anual es de 19,000 casos nuevos. A pesar de los protocolos actuales de tratamiento con quimioterapia intensa y el uso de trasplante de células troncales, la AML sigue siendo fatal para la mitad de los pacientes jóvenes diagnosticados y para casi el $80 \%$ de los pacientes con más de 60 años debido a refractariedad, recaída o mortalidad relacionada al tratamiento. A nivel genético, se ha encontrado la presencia recurrente de mutación en el gen DNMT3A en un 6 al 36\% de los pacientes con AML, aunque el mecanismo por el cual ésta mutación puede contribuir a la transformación leucémica aun no es claro. De igual manera, se ha visto que los distintos subtipos de AML tienen patrones específicos de metilación de citosinas en el genoma y están asociados a translocaciones específicas y a fusión de genes como ocurre con RUNX1-RUNX1T1 [AML1-ETO], PML-RARA, mutaciones en CEBPA y en NPM1. El hecho de que mutaciones en 
genes que codifican factores de transcripción estén asociadas con un único patrón de metilación enfatiza la relación entre reguladores transcripcionales defectuosos y las alteraciones epigenéticas.

La leucemia linfocítica crónica (CLL) por otro lado, es una enfermedad mieloproliferativa que se caracteriza por la acumulación de linfocitos $B$ maduros en la sangre, médula ósea, nódulos linfáticos y otros tejidos linfoides. Representa el $30 \%$ de todas las leucemias en los adultos y es una enfermedad de la vejez, más comúnmente diagnosticada en Europa Occidental y Norte América. La comparación entre muestras de CLL y tejido sano ha permitido la identificación de tres grupos de CLL, con respecto al nivel de diferenciación alcanzado asociado a desmetilación (llamado programación). Regiones con sitios de unión a AP-1, EBF1 y RUNX3 están altamente enriquecidas en diferencias entre grupos programados como bajo e intermedio, y muestras programadas como bajo se han asociado con ZAP70 hipometilado y mal pronóstico. Otras familias de factores de transcripción (NFAT, EGR, SP1 y E2A) también están involucradas en anormalidades de metilación específica de CLL. En esta patología se ha observado que existe un grado de heterogeneidad en los patrones de metilación de alelos mucho más alto que en otros canceres. Lo que significa que, a diferencia de lo que pasa en una célula normal en la cual un alelo está totalmente metilado o totalmente desmetilado, las células de la CLL tienen copias parcialmente metiladas, aunque las consecuencias funcionales de esta metilación desordenada aún no se comprenden. Sin embargo, se observa que a mayor desorden de metilación peor es el pronóstico.

La pérdida de H3K9me3 se ha encontrado en regiones importantes de promotores de genes en pacientes con leucemia mieloide aguda (LMA), mientras que en la leucemia linfocítica aguda (ALL) se presenta hipometilación y sobreexpresión de IL2RA (CD25), el cual se considera un candidato potencial para ser un marcador de quimioresistencia. 


\section{Metiloma en canceres de sistema nervioso}

Los tumores cerebrales se caracterizan por su alta morbilidad y mortalidad debida a su localización y a su naturaleza difusa e invasiva. Los gliomas y los meningiomas son los más comunes y surgen de las células troncales neurogliales. El glioma es el tumor cerebral primario más frecuente y devastador en los adultos, se pueden originar en cerebro y médula espinal a partir de las células que rodean y sustentan a las neuronas, estos tumores reciben el nombre de acuerdo al tipo de célula glial afectada (astrocitomas, oligodendrogliomas y ependimomas) y son altamente resistentes al tratamiento. Especialmente los astrocitomas suelen ser malignos en un alto porcentaje de los casos y pueden dar lugar al desarrollo de un glioblastoma, sin embargo estos aparecen de novo con mayor frecuencia y su tasa de sobrevida mayor a un año es muy rara.

La metilación aberrante del DNA se ha asociado con el desarrollo y progresión del tumor e inactivación de genes por hipermetilación entre los cuales se han identificado a ANKDD1A, GAD1, HIS1H3E, PCDHA8, PHOX2B, SIX3 y SST. Ahora se ha agregado una causa más de complejidad al desarrollo de las enfermedades, ya que para ésta patología se encontró que la expresión del RNA no codificante miR-185 produce la activación de la DNMT1. Los tumores cerebrales usualmente son tratados con cirugía, radioterapia y quimioterapia con temozolomida (TMZ) seguido de TMZ adyuvante. El tratamiento con este agente alquilante mejora significativamente la supervivencia global y libre de progresión en los pacientes con diagnostico reciente, aunque la duración de la supervivencia tiene una media de 1517 meses. Sin embargo, el estatus de la metilación de la región promotora de la metil transferasa de $\mathrm{O}^{6}$-metilguanina (MGMT), una proteína de reparación de DNA que remueve aductos de DNA, como los inducidos por los agentes alquilantes, está correlacionado con la respuesta o resistencia a agentes alquilantes.

La expresión de MGMT puede ser reprimida por metilación de su promotor dando lugar a una mejor respuesta a fármacos alquilantes debido a la función de MGMT como antagonista de TMZ, que conduce a la resistencia del tumor. En un análisis del tratamiento de glioblastoma fase III se demostró que los pacientes con metilación del promotor de MGMT tuvieron mayor sobrevivencia luego del 
tratamiento, que aquellos con tumores sin metilación de MGMT, por lo que la metilación en este gen es una excepción a lo encontrado en otros tumores donde la metilación del promotor de un gen es indicativo de un mal pronóstico.

Entre las diferencias observadas en algunos tipos de glioblastomas, la hipometilación de los promotores de los genes BEX1, BEX2, p16INK4, p14ARF, GATA6, EMP3, RAR-beta, TES y TIMP3 es característica del glioblastoma difuso, mientras que CYB5R2 hipometilado es característico del glioblastoma multicéntrico. El neuroblastoma por otro lado, es un tumor infantil que se origina de células precursoras del sistema nervioso simpático, el pronóstico de esta enfermedad es heterogéneo y va desde una excelente sobrevivencia a largo plazo hasta un alto riesgo con resultados fatales, por lo que los pacientes son estratificados en grupos de riesgo para determinar el tratamiento más apropiado. El diagnostico se basa en una combinación de parámetros clínicos y biológicos que sigue siendo inadecuado para un buen pronóstico. A la fecha se ha reportado metilación de los promotores de TNFRSF10D, CASP8, ZMYND10, RASSF1A, KRT19, GNAS, HIST1H3C, RB1y TDGF1 y un fenotipo metilador de islas CpG.

\section{Metiloma en cáncer de páncreas}

El 95\% de los casos de cáncer pancreático surge de las células exócrinas a partir de las cuales se desarrolla el tipo más común, el adenocarcinoma ductal pancreático (PDAC). Este surge de lesiones precursoras como la neoplasia intraepitelial pancreática (PanIN) y la neoplasia mucinosa papilar intraductal (IPMN). Actualmente el PDAC es uno de los tumores sólidos más letales. Con una sobrevivencia media de alrededor de 6 meses después del diagnóstico y una tasa de sobrevivencia a 5 años menor al 5\%, ocupa el séptimo lugar como causa de muerte por cáncer a nivel mundial. Este cáncer tiene pocos síntomas iniciales y se desarrolla rápidamente por lo que muchos carcinomas son confirmados en un estado avanzado sin posibilidad de tratamiento por cirugía. Invade rápidamente los tejidos linfático, perineural y vascular circundantes debido al microambiente tumoral altamente favorecedor. El estroma desmoplástico denso del PDAC contiene fibroblastos activados, células inflamatorias, citosinas inflamatorias y factores de 
crecimiento que favorecen un microambiente inflamatorio, que a su vez proveen las señales de sobrevivencia y proliferación para el desarrollo, progresión y resistencia del tumor al tratamiento. Los mecanismos subyacentes para su fenotipo agresivo no se conocen por completo, entre las extensas anormalidades moleculares que presenta se han identificado mutaciones en los genes KRAS2, CDKN1A/p16, CDKN2A, TP53 y SMAD4/DPC4/MADH4.

Los promotores de los genes supresores de tumores APC, BRCA1, p16 ${ }^{\text {INK4 }}$ son las regiones más frecuentemente metiladas en las neoplasias pancreáticas. $A$ través del análisis de genoma completo para búsqueda de metilación, se han encontrado genes metilados en mecanismos clave, como TGF- $\beta$, WNT, señalización de integrinas, adhesión celular y activación de células estrelladas. Por otro lado, la hipermetilación del promotor de WNK2 se ha observado en neoplasias intraductales pancreáticas potenciando el crecimiento del tumor a través de la vía ERK-MAPK. WNK2 es una cinasa de serina-treonina citoplásmica cuyo silenciamiento también se presenta en los gliomas LLC, LMA y en meningiomas. Otro participante clave es la proteína MBD1 (proteína 1 con dominio de unión a metil- $\mathrm{CpG}$ ) quien se une a islas $\mathrm{CpG}$ favoreciendo que las células pancreáticas adquieran un fenotipo invasivo. Forma un complejo con Twist y SIRT-1 sobre el promotor de CDH1, lo que tiene como resultado la regulación a la baja de la cadherina-E favoreciendo la transición epitelio-mesénquima, proceso crucial utilizado por las células tumorales para su movilización hacia otros tejidos.

p16 y RASSF1A otros genes supresores de tumor, se han encontrado altamente metilados, un comportamiento similar se ha reportado para el neuropéptido Metencefalina, ppENK en más del $90 \%$ de casos analizados. La metilación de NPTX2 para diferenciar entre tejido tumoral y otras patologías pancreáticas tiene una sensibilidad y especificidad del 80 y $76 \%$ respectivamente, lo que lo hace un buen marcador de diagnóstico diferencial. Por otro lado, la hipermetilación del factor de necrosis tumoral 10c, TNFRSF10C y del inductor de condensación de cromatina apoptótica 1, ACIN1 se ha asociado con una sobrevivencia más corta. Se ha encontrado también que niveles muy altos de metilación están relacionados con 
dispersión perineural de las células cancerosas. La metilación del gen supresor de tumor harakiri, HRK es un cambio determinante en el fenotipo tumoral ya que al silenciarse su expresión la cuenta de células apoptóticas baja, y se favorece el desarrollo y progresión del tumor.

Metiloma en cáncer de ovario

El cáncer ovárico ocupa el séptimo lugar como causa de cáncer en las mujeres a nivel mundial, tiene la mayor incidencia en países económicamente desarrollados, generalmente ocurre de forma esporádica, lo cual resulta en un bajo riesgo para desarrollarlo (2-5\%), mientras que aquellas mujeres que tienen predisposición genética representan solo el $5-10 \%$ de las afectadas. La incidencia es más alta entre los 50-70 años y su tasa de mortalidad se debe a que es asintomático y se le diagnostica en etapas avanzadas en el $75 \%$ de los casos, cuando la enfermedad ya se ha dispersado al abdomen.

Este cáncer incluye a diversos tipos histológicos, con un origen epitelial para la mayoría, donde el carcinoma seroso de alto grado es el responsable del $70-80 \%$ de los casos, seguido de los tipos raros, que incluyen al cáncer de células claras (3\%), endometrioide $(<5 \%)$ y el mucinoso con menos del $3 \%$. Mientras que los tipos no epiteliales comprenden a los tumores raros de células germinales y a los estromales. Pacientes en estados avanzados de la enfermedad tienen una tasa de sobrevivencia de solo el $30 \%$ y los métodos de detección desafortunadamente tienen altas tasas de falsos negativos, además de baja especificidad y sensibilidad. Las mujeres con predisposición llevan mutaciones en la línea germinal para genes involucrados en respuesta a daño al DNA, en los genes BRCA1, BRCA2 y/o p53.

Algunos investigadores han sugerido que la determinación del estado de metilación de un panel de genes, más que de un gen individual puede dar lugar a un diagnóstico más específico y sensible. Se ha identificado la metilación de algunos genes importantes para el desarrollo y progreso de esta enfermedad entre los que se encuentran HOXA9, metilado en tumores serosos de alto grado. HOXA9 regula 
la diferenciación de los conductos de Müller en oviductos, su metilación refleja una pérdida de la plasticidad transcripcional durante el desarrollo de la enfermedad y un cambio hacia la desdiferenciación epitelial. Por otro lado, la metilación de la molécula de adhesión celular de unión a opioide, OPCML se vio asociada con el estado, tipo histológico, grado y la ascitis (presencia de líquido seroso en el espacio entre el peritoneo visceral y el peritoneo parietal). La metilación de CpGs específicas, como en el caso del promotor de ZIC1/4, se ha asociado con una corta progresión libre de enfermedad. Además de mutaciones, también hay alteración en la metilación de al menos un gen involucrado en reparación BRCA1, MGMT o GSTP1, lo que se correlaciona con una mejor respuesta a la quimioterapia. De importancia pronostica se ha visto la metilación en el homologo 1 de mutL, MLH1 detectada en suero durante la recaída, tiene valor pronóstico de sobrevivencia más corta y está correlacionado con mayor inestabilidad de microsatélites. Más recientemente se asoció la hipermetilación de RUNX3 y CAMK2N1 con un mal desenlace clínico.

\section{Metiloma en cáncer hepático}

El carcinoma hepatocelular es el tipo más común de cáncer hepático primario y explica el $90 \%$ de todos los casos, su distribución global está asociada con la prevalencia de sus factores de riesgo dominantes. La infección por virus de hepatitis B (HBV) es la principal causa del carcinoma hepatocelular en Asia Oriental y África sub-Sahariana en un $70 \%$. En Europa y Norte América el factor de riesgo es el virus de hepatitis $\mathrm{C}$ en un $50-70 \%$, mientras que el consumo excesivo de alcohol que lleva a esteatohepatitis alcohólica contribuye en un $20 \%$ de los casos. El carcinoma hepatocelular generalmente surge de una enfermedad de curso crónico con cirrosis hepática, aunque puede desarrollarse en hígado no cirrótico solo en el $20 \%$ de los casos. Entre los genes anormalmente metilados están RASSF1A, GSTP1, CHRNA3 y DOK1, genes que se han encontrado epigeneticamente alterados en otros tipos de tumores. Una de las vías afectadas por cambios en la metilación del genoma es la vía de Wnt (vía que regula la proliferación, diferenciación, destino y muerte celular 
en el desarrollo embrionario y en cáncer), particularmente DKK3, quien participa en la inhibición de esta vía y cuya expresión se encuentra disminuida en diversos tumores sólidos. Algo interesante es que se ha encontrado que bajos niveles de hipometilación conforman el mecanismo epigenético clave en el hepatoblastoma, fenómeno que podría tener su origen en la inhibición de las DNMTs lo que llevaría a una desmetilación pasiva de diversos genes.

\section{Metilación y RNA en cáncer}

Solo $2 \%$ del genoma total corresponde a genes que codifican proteínas el restante 98\% es transcrito en RNAs no codificantes (ncRNAs), que en el pasado eran considerados como ruido transcripcional pero que ahora se sabe desempeñan un papel regulador crucial en la diferenciación celular y el crecimiento y metabolismo de los organismos. Los ncRNAs incluyen a los RNAs de transferencia, los RNAs nucleares pequeños, RNAs ribosomales y los RNAs nucleolares pequeños. Otro grupo aun mayor de ncRNAs está formado por los RNAs largos no codificantes (IncRNAs).

Los micro RNAs (miRNAs) son RNAs pequeños no codificantes de cadena sencilla, de 19-25 nucleótidos de largo, involucrados en varios procesos biológicos como la sobrevivencia, apoptosis, ciclo celular y regulación genética. La biogénesis de los miRNAs involucra a la RNA polimerasa II (RNA pol II) la cual transcribe los transcritos primarios conocidos como pri-miRNA, estos a su vez son divididos por Drosha, una RNAsa III en los precursores de los miRNAs, los pre-miRNAs. Los premiRNAs son transportados fuera del núcleo por medio de la exportina 5 , cuando se ubican en el citoplasma su procesamiento corre por cuenta de Dicer, quien los corta en miRNAs de cadena sencilla. El miRNA maduro se acopla sobre el complejo de silenciamiento inducido por RNA, el complejo RISC, de esta forma se une al RNAm blanco y desencadena su degradación o la su represión de su traducción. Específicamente se unen a la región no traducida 3' o UTR3' de la molécula de RNAm, su regulación ocurre a nivel de todos los tipos celulares y su expresión aberrante está implicada en diversos procesos patológicos que van desde la 
inflamación, apoptosis, infartos, enfermedad de Alzheimer, osteoporosis, diabetes hasta el cáncer.

Los miRNAs funcionan silenciando la expresión génica y pueden actuar como supresores o como oncogenes en diferentes tipos de cáncer. La expresión aberrante de los miRNAs y sus genes blanco tiene un papel crítico en el inicio del cáncer, su progresión y metástasis. En el cáncer gástrico los datos de secuenciación de miRNAs han permitido obtener un patrón aberrante de metilación en el DNA de mir miR-196B, miR-212, miR-148A, miR-219-1 y miR-219-2 en el subtipo EBVpositivo, mientras que miR-9-1, miR-137, miR-34C y mir-9-3 además de estar hípermetilados en EBV tienen el mismo comportamiento en el subtipo MSI. Y de manera global, en todos los subtipos de cáncer gástrico están hípermetilados mir10B, miR-129-2, miR-124a-1, miR-124a-2 y miR-124a-3. Mientras que en el cáncer colorectal la hipermetilación del DNA causa la inactivación de miR-125a y miR-125b. En la patogénesis del glioma se ha reportado que miR-34b, let-7a-3 y miR-126 están regulados por metilación de DNA.

En el adenocarcinoma ductal pancreático la hipermetilación de miR-615-5p ocasiona su silenciamiento, lo cual afecta la regulación del gen IGF2, ya que se limita su inhibición, lo que conlleva al crecimiento e invasión tumoral.

Los IncRNAs son determinantes durante el desarrollo embrionario y en la morfogénesis de los tejidos, al actuar como co-activadores de la transcripción, en la orientación de complejos epigenéticos en el genoma, en la regulación de la traducción del RNA y su decaimiento. Recientemente se demostró que pueden funcionar como inhibidores competitivos de los miRNAs, por lo que se les considera "esponjas" de miRNAs ya que pueden disminuir los niveles de miRNAs. Estos RNAs son transcritos también por la RNA pol II, tienen un rango de longitud entre 200 nucleótidos y 100 kilobases y no tienen una clasificación precisa debido a su amplio rango de tamaño, localización y funciones. Se les clasifica como IncRNAs intergénicos, IncRNAs intrónicos, IncRNAs de función doble, IncRNAs asociados a los telómeros. Los IncRNAs interactúan con diversos complejos modificadores de la cromatina, por lo tanto, su desregulación puede impactar en la habilidad de los complejos modificadores epigenéticos para regular al epigenoma y la expresión de 
genes. Existen evidencias que apoyan que los IncRNAs pueden interactuar con las DNA metiltransferasas y afectar su actividad, en particular se han identificado interacciones entre el IncRNA TCONS_00023265 con la DNMT1.

\section{Cambios epigenéticos como biomarcadores y fármacos epigenéticos}

Desde la antigüedad ha existido el interés de tener herramientas para predecir la salud de un paciente, lo que inicialmente se hacía a través de la observación directa del paciente, evolucionó hasta el uso de biomarcadores moleculares en la actualidad, gracias al progreso en la investigación médica. Los biomarcadores sirven como indicadores moleculares del estado fisiológico de una persona, el cual puede ser analizado en sangre, orina o tejido y es importante para el manejo de una enfermedad. Cambios en su concentración sirven para hacer una estimación sobre la progresión de la enfermedad e idealmente deben tener alta sensibilidad de detección y alta especificidad.

El uso de biomarcadores moleculares a nivel clínico puede ir desde la utilización de polimorfismos de un solo nucleótido (SNPs), pasando por el uso de mutaciones bien conocidas, hasta el uso de un tipo particular de proteína secretada. Sin embargo, a pesar del creciente número de potenciales biomarcadores descritos en la literatura científica, el número de biomarcadores aprobado por la FDA (Food and Drug Administration) en Estados Unidos no se ha incrementado, sino que ha disminuido.

Las modificaciones epigenéticas son un componente importante en la etiología del cáncer y debido a su reversibilidad constituyen blancos terapéuticos prometedores para diagnostico o tratamiento y potencial como posibles biomarcadores.

El cáncer como la enfermedad compleja que es, tiene diferente respuesta al tratamiento de paciente a paciente, aun tratándose del mismo sitio primario y estado tumoral. Una de las causas por las que es difícil identificar biomarcadores para desarrollar pruebas diagnósticas para una terapia localizada es que, a la fecha, la comprensión de los mecanismos subyacentes a la enfermedad sigue siendo insuficiente. El primer biomarcador utilizado con éxito en la toma de decisiones de 
regulación por la FDA, fue el receptor 2 para el factor de crecimiento epidermal humano (HER2), para el tratamiento del cáncer de mama en 1998. La FDA aprobó el uso de la herceptina (trastuzumab) en los casos donde se presenta sobreexpresión de HER2. Además se han aprobado dos inhibidores de DNMT, vidaza y decitabina (5-aza y 5-aza-2'desoxicitidina, respectivamente) para el tratamiento de pacientes con síndrome mielodisplásico quienes desarrollan leucemia mieloide aguda. Vidaza es un nucleósido análogo que se incorpora durante la replicación y se une de forma covalente a las DNMTs reduciendo su disponibilidad, mientras que la decitabina es un análogo más potente de vidaza y tiene la ventaja de que es incorporado al DNA con mayor especificidad y no a ambos DNA y RNA, como ocurre con vidaza. Para el tratamiento del linfoma de células T y otras neoplasias hematológicas se han aprobado dos inhibidores de HDAC, vorinostat y romidepsina. Esos inhibidores de HDAC fueron diseñados para revertir la represión mediada por desacetilación de supresores de tumor, vorinostat es un ácido hidroxámico y romidepsina es un tetrapéptido cíclico. Desafortunadamente para el tratamiento de tumores sólidos las drogas epigenéticas han tenido poco éxito debido a un factor clave, la vascularización anormal de los tumores sólidos y el microambiente asociado al tumor. De manera más reciente se han estado probando en tratamientos clínicos a inhibidores de metiltransferasas de histonas como UNCO638 y DZNeP en cáncer de mama, colon y próstata; mitramicina en cáncer de pulmón o GSK343 y UNC669 en cáncer de ovario. También se están probando los inhibidores de desmetilasas de histonas como el tranilxipromide y el ORY-1001 en leucemia y síndrome mielodisplásico.

También es de valor pronóstico el análisis de los niveles de modificación en las histonas, ya que se ha observado que el aumento en la prevalencia de células con niveles globales de modificaciones en las histonas por debajo de lo normal en pacientes con cáncer, los lleva a un pronóstico de mala evolución clínica, es decir, a tener mayor riesgo de recurrencia del tumor y/o disminución en la probabilidad de sobrevivencia. De hecho, se ha observado que también puede ser una herramienta útil para predecir la respuesta a algunos agentes quimioterapéuticos, proveyendo información para la toma de decisiones en la elección y curso de la terapia a aplicar. 
Ya que por ejemplo se ha encontrado que bajos niveles de H3K4me2 están asociados con un mal pronóstico en cánceres de próstata, pulmón y riñón. Bajos niveles de H3K18ac y H3K9me3 son predictores de mal pronóstico para cáncer de pulmón y de riñón, de igual manera, pacientes con cáncer de pulmón que presentan altos niveles de H3K9ac tienen una tasa de sobrevivencia más baja.

El mejor marcador de metilación en el cáncer de próstata es la hipermetilación del gen para la glutation S-transferasa (GSTP1), debido a que se encuentra hípermetilado en el $80-90 \%$ de los hombres con cáncer de próstata. La hipermetilación de GSTP1 es un parámetro muy útil en el diagnostico ya que, permite distinguir entre el cáncer propiamente y lesiones como la hiperplasia prostática benigna.

En el cáncer colorectal la Septina9 metilada (mSeptin9) es uno de los biomarcadores epigenéticos mas estudiados, la mSeptin9 se detecta en suero o plasma de los pacientes y tiene una sensibilidad del 51.1 al $90 \%$ y una especificidad de 72.9 a 96.5\%. Comercialmente están disponibles la prueba Epi proColon (basada en el análisis de la mSeptin9) cuya tasa de eficiencia positiva es del $76.7 \%$ y ColoSure para analizar el exón 1 de gen de vimentina en heces fecales. De hecho, en heces fecales se tienen identificados dos marcadores más, el receptor para progesterona y MGMT que se encuentran hípermetilados.

Hasta ahora el marcador de elección para detección de cáncer pancreático es el antígeno carbohidrato 19-9 (CA19-9), el cual no es útil para la localización del tumor en etapas tempranas. Dado que la detección temprana es clave para el diagnóstico de cáncer pancreático, los biomarcadores de metilación se consideran buenos indicadores para la detección de lesiones precursoras y se ha desarrollado la Base de datos de metilación para cáncer pancreático que actualmente cuenta con 65,000 entradas sobre el estado de metilación de más de 4000 genes. Detectando la metilación aberrante de BNC1 y ADAMTS1 en tejidos fijados y embebidos en parafina y en muestras de suero, ha sido posible detectar etapas tempranas con mayor frecuencia que con el CA19-9. En estudios recientes sobre tratamiento para el cáncer pancreático se reporta que el uso de decitabina combinado con emodin 
(extracto de una hierba medicinal china) aumenta los niveles de expresión de p16, RASSF1A y ppENK y baja los niveles de expresión de las metiltransferasas DNMT1 y DNMT3, lo que se traduce en una prometedora estrategia de tratamiento clínico para un padecimiento con una alta tasa de mortalidad.

Mientras que en el cáncer de próstata se han identificado como biomarcadores a ABHD9, GSTP1, HOXD3, PTGS2, RARB, RASSF1A, HLHE40, BCL6 e ITGA9. Sin embargo, el biomarcador de metilación potencial es GSTP1, la glutatión Stransferasa $\mathrm{P} 1$, este gen codifica para una enzima necesaria para la desintoxicación y protección del DNA de metabolitos oxidantes. El estado de metilación de GSTP1 permite discriminar entre cáncer de próstata e hiperplasia benigna y predecir la recurrencia de enfermedad.

A pesar de todo este conocimiento, no ha sido fácil determinar la conexión entre anormalidades en la metilación del DNA y la enfermedad, porque aún no existe la certeza de que la enfermedad no sea la causa de los cambios observados en los patrones de metilación o si los cambios son causados por uno o varios factores de riesgo. Actualmente no está comprendida del todo, la interacción entre metilación de DNA y la expresión de los genes, ya que, aunque la metilación de los promotores se asocia con el silenciamiento, también es cierto que la metilación en el cuerpo del gen puede asociarse positivamente con la transcripción. Como tampoco ha sido fácil establecer el uso de fármacos inhibidores en la práctica clínica, debido a que las proteínas blanco pueden tener efectos opuestos en las células como ocurre con los supresores de tumores versus los oncogenes. 


\section{Referencias}

- Alokail M, Alenad M. DNA Methylation in: A Concise Review of Molecular Pathology of Breast Cancer. Edited by Mehmet Gunduz. 2015, 55 pag. ISBN 978-953-51-2030-8

- Bartel DP. MicroRNAs: genomics, biogenesis, mechanism, and function. Cell 2004;116:281-97

- Baxter E, Windloch K, Gannon F, Lee JS. Epigenetic regulation in cancer progression. Cell Biosci. 2014 Aug 19;4:45.

- Bibikova M,Barnes B, Tsan C, Ho V, Klotzle B, Le JM, et al. High density DNA methylation array with single CpG site resolution. Genomics. Oct 2011; 98(4), 288-295.

- Brock MV, Hooker CM, Ota-Machida E, Han Y, Guo M, Ames S, et al. DNA methylation markers and early recurrence in stage I lung cancer. $\mathrm{N}$ Engl J Med. 2008 Mar 13;358(11):1118-28

- Brownlee PM, Meisenberg C, Downs JA. The SWI/SNF chromatin remodeling complex: Its role in maintaining genome stability and preventing tumourigenesis. DNA Repair (Amst). 2015 Ago;32:127-33

- Casciello F, Windloch K, Gannon F, Lee JS. Functional Role of G9a Histone Methyltransferase in Cancer. Front Immunol. 2015 Sep 25;6:487.

- Chauhan R, Lahiri N. Tissue- and Serum-Associated Biomarkers of Hepatocellular Carcinoma. Biomark Cancer. 2016 Jul 4;8(Suppl 1):37-55

- Decock A, Ongenaert M, Cannoodt R, Verniers K, De Wilde B, Laureys G, et al. Methyl-CpG-binding domain sequencing reveals a prognostic methylation signature in neuroblastoma. Oncotarget. 2016 Ene 12;7(2):1960-72.

- Diaz-Lagares A, Mendez-Gonzalez J, Hervas D, Saigi M, Pajares MJ, Garcia $D$, et al. A novel epigenetic signature for early diagnosis in lung cancer. Clin Cancer Res. 2016 Feb 3.

- Dmitriev AA, Rosenberg EE, Krasnov GS, Gerashchenko GV, Gordiyuk VV, Pavlova TV, et al. Identification of Novel Epigenetic Markers of Prostate Cancer by Notl-Microarray Analysis. Dis Markers. 2015;2015:241301 
- Ek WE, Rask-Andersen M, Johansson A. The role of DNA methylation in the pathogenesis of disease: what can epigenome-wide association studies tell? Epigenomics. 2016 Jan;8(1):5-7.

- Feinberg AP. Cancer epigenetics is no Mickey Mouse. Cancer Cell. 2005 Oct;8(4):267-8.

- Gao W, Gu Y, Li Z, Cai H, Peng Q, Tu M, et al. miR-615-5p is epigenetically inactivated and functions as a tumor suppressor in pancreatic ductal adenocarcinoma. Oncogene. 2015 Mar 26;34(13):1629-40.

- Graham, J.S.; Kaye, S.B.; Brown, R. The promises and pitfalls of epigenetic therapies in solid tumours. Eur J Cancer. 2009 May;45(7):1129-36.

- Guo J, Yang Y, Yang Y, Linghu E, Zhan Q, Brock MV, et al. RASSF10 suppresses colorectal cancer growth by activating P53 signaling and sensitizes colorectal cancer cell to docetaxel. Oncotarget. 2015 Feb 28;6(6):4202-13

- Guo T, Ren Y, Wang B, Huang Y, Jia S, Tang W, et al. Promoter methylation of BRCA1 is associated with estrogen, progesterone and human epidermal growth factor receptor-negative tumors and the prognosis of breast cancer: A meta-analysis. Mol Clin Oncol. 2015 Nov;3(6):1353-1360.

- Häfner N, Steinbach D, Jansen L, Diebolder H, Dürst M, Runnebaum IB. RUNX3 and CAMK2N1 hypermethylation as prognostic marker for epithelial ovarian cancer. Int J Cancer. 2016 Ene 1;138(1):217-28.

- Hajjari M, Salavaty A. HOTAIR: an oncogenic long non-coding RNA in different cancers. Cancer Biol Med. 2015 Mar;12(1):1-9

- Hamashima C, Shibuya D, Yamazaki H, Inoue K, Fukao A, Saito H, et al. The Japanese guidelines for gastric cancer screening. Jpn J Clin Oncol. 2008 Apr;38(4):259-67.

- Holliday R. A new theory of carcinogenesis. Br J Cancer. 1979 Oct;40(4):51322.

- Hong H, Goodsaid F, Shi L, Tong W. Molecular biomarkers: a US FDA effort. Biomark Med. 2010 Apr;4(2):215-25. 
- Horiguchi K, Tomizawa Y, Tosaka M, Ishiuchi S, Kurihara H, Mori M, et al. Epigenetic inactivation of a RAS association domain family protein from the lung tumour suppressor locus 3p21.3. Oncogene. 2003 Oct 30;22(49):78625.

- Kishore K, de Pretis S, Lister R, Morelli MJ, Bianchi V, Amati B, et al. methylPipe and compEpiTools: a suite of $R$ packages for the integrative analysis of epigenomics data. BMC Bioinformatics. 2015 Sep 29;16:313.

- Liao WW, Yen MR, Ju E, Hsu FM, Lam L, Chen PY. MethGo: a comprehensive tool for analyzing whole-genome bisulfite sequencing data. BMC Genomics. 2015 Dec 9;16 Suppl 12:S11.

- $\operatorname{Lim}$ B, Kim JH, Kim M, Kim SY. Genomic and epigenomic heterogeneity in molecular subtypes of gastric cancer. World J Gastroenterol. 2016 Jan $21 ; 22(3): 1190-201$.

- Luchini C, Veronese N, Solmi M, Cho H, Kim JH, Chou A, et al. Prognostic role and implications of mutation status of tumor suppressor gene ARID1A in cancer: a systematic review and meta-analysis. Oncotarget. 2015 Nov 17;6(36):39088-97.

- Ludwig JA, Weinstein JN. Biomarkers in cancer staging, prognosis and treatment selection. Nat Rev Cancer 5:845-856

- Malih S, Saidijam M, Malih N. A brief review on long noncoding RNAs: a new paradigm in breast cancer pathogenesis, diagnosis and therapy. Tumour Biol. 2015 Dec 11

- Martin TC, Yet I, Tsai PC, Bell JT. coMET: visualisation of regional epigenome-wide association scan results and DNA co-methylation patterns. BMC Bioinformatics. 2015 Apr 28;16:131.

- Maschietto M, Rodrigues TC, Kashiwabara AY, Souza de Araujo ÉS, Marques Aguiar TF, Lima da Costa CM, da Cunha IW, Reis Vasques LD, Cypriano M, Brentani H,Caminada de Toledo SR, Pearson PL, Carraro DM, Rosenberg C, Krepischi AC. DNA methylation landscape of hepatoblastomas reveals arrest at early stages of liver differentiation and cancer-related alterations. Oncotarget. 2016 Dec 25 
- Merry CR, Forrest ME, Sabers JN, Beard L, Gao XH, Hatzoglou M, et al. DNMT1-associated long non-coding RNAs regulate global gene expression and DNA methylation in colon cancer. Hum Mol Genet. 2015 Nov 1;24(21):6240-53

- Mockus SM, Patterson SE, Statz C, Bult CJ, Tsongalis GJ. Clinical Trials in Precision Oncology. Clin Chem. 2016 Mar;62(3):442-8.

- Mullapudi N, Ye B, Suzuki M, Fazzari M, Han W, Shi MK, et al. Genome Wide Methylome Alterations in Lung Cancer. PLoS One. 2015 Dec 18;10(12).

- Oh JH, Jung SH, Hong SJ, Rhyu MG. DNA Methylation as Surrogate Marker For Gastric Cancer. J Cancer Prev. 2015 Sep;20(3):172-8

- Olkhov-Mitsel E, Zdravic D, Kron K, van der Kwast T, Fleshner N, Bapat B. Novel multiplex MethyLight protocol for detection of DNA methylation in patient tissues and bodily fluids. Sci Rep. 2014 Mar 21;4:4432.

- Pan FP, Zhou HK, Bu HQ, Chen ZQ, Zhang H, Xu LP, et al. Emodin enhances the demethylation by 5-Aza-CdR of pancreatic cancer cell tumor-suppressor genes P16, RASSF1A and ppENK. Oncol Rep. 2016 Jan 13

- Patai ÁV, Valcz G, Hollósi P, Kalmár A, Péterfia B, Patai Á, et al. Comprehensive DNA Methylation Analysis Reveals a Common Ten-Gene Methylation Signature in Colorectal Adenomas and Carcinomas. PLoS One. 2015 Aug 20;10(8):e0133836

- Payne SR. From discovery to the clinic: the novel DNA methylation biomarker mSEPT9 for the detection of colorectal cancer in blood. Epigenomics 2010; 2: 575-585.

- Pei Y, Kano J, lijima T, Morishita Y, Inadome Y, Noguchi M. Overexpression of Dickkopf 3 in hepatoblastomas and hepatocellular carcinomas. Virchows Arch. 2009 Jun;454(6):639-46

- Rauscher GH, Kresovich JK, Poulin M, Yan L, Macias V, Mahmoud AM, et al. Exploring DNA methylation changes in promoter, intragenic, and intergenic regions as early and late events in breast cancer formation. BMC Cancer. 2015 Oct 29;15:816. 
- Rieder D, Amort T, Kugler E, Lusser A, Trajanoski Z. meRanTK: methylated RNA analysis ToolKit. Bioinformatics. 2015 Nov 4. pii: btv647.

- Rodríguez-Paredes M, Esteller M. Cancer epigenetics reaches mainstream oncology. Nat Med. 2011 oMar;17(3):330-9.

- Roos-Weil D, Nguyen-Khac F, Bernard OA. Chronic lymphocytic leukemia: Time to go past genomics? Am J Hematol. 2016 Jan 22.

- Seligson DB, Horvath S, McBrian MA, Mah V, Yu H, Tze S, et al. Global levels of histone modifications predict prognosis in different cancers. Am J Pathol. 2009 May;174(5):1619-28.

- Shain KH, Yarde DN, Meads MB, Huang M, Jove R, Hazlehurst LA, et al. Beta1 integrin adhesion enhances IL-6-mediated STAT3 signaling in myeloma cells: implications for microenvironment influence on tumor survival and proliferation. Cancer Res. 2009;69(3):1009-1015

- Stirzaker C, Zotenko E, Song JZ, Qu W, Nair SS, Locke WJ, et al. Methylome sequencing in triple-negative breast cancer reveals distinct methylation clusters with prognostic value. Nat Commun. 2015 Feb 2;6:5899.

- Sukowati CH, El-Khobar KE, le SI, Anfuso B, Muljono DH, Tiribelli C. Significance of hepatitis virus infection in the oncogenic initiation of hepatocellular carcinoma. World J Gastroenterol. 2016 Jan 28;22(4):1497512

- Sundar S, Neal RD, Kehoe S. Diagnosis of ovarian cancer. BMJ. 2015 Sep 1;351:h4443

- Tang D, Kryvenko ON, Mitrache N, Do KC, Jankowski M, Chitale DA, et al. Methylation of the RARB gene increases prostate cancer risk in black Americans. J Urol. 2013 Jul;190(1):317-24

- van der Weyden L, Adams DJ. The Ras-association domain family (RASSF) members and their role in human tumourigenesis. Biochim Biophys Acta. 2007 Sep; 1776(1):58-85.

- Wang ML, Bailey NG. Acute Myeloid Leukemia Genetics: Risk Stratification and Implications for Therapy. Arch Pathol Lab Med. 2015 Oct;139(10):121523 
- Warren JD'1, Xiong W, Bunker AM, Vaughn CP, Furtado LV, Roberts WL, et al. Septin 9 methylated DNA is a sensitive and specific blood test for colorectal cancer. BMC Med. 2011 Dec 14;9:133.

- Wouters BJ, Delwel R. Epigenetics and approaches to targeted epigenetic therapy in acute myeloid leukemia. Blood. 2016 Jan 7;127(1):42-52

- Xing BL, Li T, Tang ZH, Jiao L, Ge SM, Qiang X, et al. Cumulative methylation alternations of gene promoters and protein markers for diagnosis of epithelial ovarian cancer. Genet Mol Res. 2015 May 4;14(2):4532-40.

- Yan H, Tian S, Slager SL, Sun Z, Ordog T. Genome-Wide Epigenetic Studies in Human Disease: A Primer on -Omic Technologies. Am J Epidemiol. 2016 Jan 15;183(2):96-109.

- Zhang Z, Tang H, Wang Z, Zhang B, Liu W, Lu H, et al. MiR-185 targets the DNA methyltransferases 1 and regulates global DNA methylation in human glioma. Mol Cancer. 2011 Sep 30;10:124 